\title{
Effect of trace mineral supplementation on selected minerals, energy metabolites, oxidative stress, and immune parameters and its association with uterine diseases in dairy cattle
}

\author{
M. L. S. Bicalho, ${ }^{*}$ F. S. Lima, ${ }^{*}$ E. K. Ganda, ${ }^{*}$ C. Foditsch, ${ }^{*}$ E. B. S. Meira Jr., ${ }^{*}$ V. S. Machado, ${ }^{*}$ A. G. V. Teixeira, ${ }^{*}$ \\ G. Oikonomou, ${ }^{*}$ R. O. Gilbert, $\dagger$ and R. C. Bicalho*1 \\ *Department of Population Medicine and Diagnostic Sciences, and \\ †Department of Clinical Sciences, College of Veterinary Medicine, Cornell University, Ithaca, NY 14853
}

\section{ABSTRACT}

The objective of this study was to evaluate the relationship between selected minerals' serum levels, energy metabolites, oxidative stress indicators, IL-8 and haptoglobin levels, and the potential for uterine diseases. Additionally, we investigated the effect of injectable trace mineral supplementation (ITMS) on metabolism, immune function, and animal health under field conditions involving a dairy herd with high milk production. The study was conducted in 1 dairy farm located near Ithaca, New York, with 270 multiparous cows were enrolled from October 3, 2012 until January 10, 2013. Cows were randomly allocated into 1 of 2 treatments groups: ITMS or control. Cows randomly assigned to the ITMS group received 2 injections of trace minerals at 230 and $260 \mathrm{~d}$ of gestation; each injection contained $300 \mathrm{mg}$ of $\mathrm{Zn}, 50 \mathrm{mg}$ of $\mathrm{Mn}, 25 \mathrm{mg}$ of Se, and $75 \mathrm{mg}$ of $\mathrm{Cu}$. Retained placenta (RP) and metritis were diagnosed and treated by trained farm personnel. Clinical endometritis evaluation was performed by the investigators. Blood mineral levels, plasma nonesterified fatty acids and serum $\beta$-hydroxybutyrate concentrations, plasma IL-8 concentrations, serum haptoglobin concentration, and serum superoxidase dismutase and plasma glutathione peroxidase activities were measured at various time points before and after calving. Four groups of mixed general linear models were fitted to the data using MIXED procedure of SAS. Injectable trace mineral-supplemented cows had increased serum concentration of $\mathrm{Cu}$, Se, and Zn. Conversely, ITMS did not affect energy metabolites or immune and oxidative stress parameters. Serum concentration of $\mathrm{Ca}, \mathrm{Cu}, \mathrm{K}$, $\mathrm{Mg}, \mathrm{Mo}, \mathrm{Ps}, \mathrm{Pt}$, Se, and $\mathrm{Zn}$ varied according to days relative to parturition. Cows with $\mathrm{RP}$ had reduced serum concentrations of $\mathrm{Ca}, \mathrm{Mg}, \mathrm{Mo}$, and $\mathrm{Zn}$ when

Received December 13, 2013.

Accepted March 31, 2014.

${ }^{1}$ Corresponding author: rcb28@cornell.edu compared with cows without RP. Cows affected with metritis had significantly lower serum concentrations of $\mathrm{Ca}$, Mo, soluble $\mathrm{P}$, total $\mathrm{P}$, Se, and $\mathrm{Zn}$ than nonaffected cows. Serum concentration of $\mathrm{Ca}, \mathrm{Cu}, \mathrm{Mo}$, and $\mathrm{Zn}$ were reduced in cows diagnosed with endometritis in comparison to nonaffected ones.

Key words: retained placenta, metritis, mineral, oxidative stress

\section{INTRODUCTION}

Postpartum uterine diseases, such as metritis, endometritis, and retained placenta $(\mathbf{R P})$, are important for animal welfare reasons, as they contribute to cow discomfort and elimination from the herd and are associated with profoundly affected reproductive performance, reduced milk yield, and treatment costs. Metritis and endometritis are commonly associated with mixed bacterial infection of the uterus, including Escherichia coli, Trueperella pyogenes, and Fusobacterium necrophorum (Bicalho et al., 2012). A contributory factor increasing susceptibility to bacterial infections and metritis development are the challenges observed during the periparturient period leading to physiological stress (Drackley, 1999), which dramatically alters metabolism to supply the mammary gland with nutrients for milk synthesis (Bauman and Currie, 1980; Goff et al., 2002). Additionally, the high nutritional requirements for parturition and initiation of lactation causes reduced DMI, negative energy balance (Roche et al., 2009), and oxidative stress, which altogether also contribute to dairy cows increased susceptibility to develop uterine diseases (Sordillo and Aitken, 2009).

For instance, subclinical mineral deficiency of Se has been associated with immunosuppression (Sordillo and Aitken, 2009) and reproductive failure (Spears and Weiss, 2008), subclinical deficiency of Zn was associated with impaired growth (Enjalbert et al., 2006), and subclinical deficiency of $\mathrm{Ca}$ was associated with decreased milk production (Oetzel, 2013). Cows with subclinical 
hypocalcemia have reduced blood neutrophil counts as well as impaired neutrophil function and increased incidence of metritis compared with normocalcemic cows (Martinez et al., 2012). Additionally, other trace minerals, such as Se, can be effective in reducing oxidative stress, and have a tremendous effect on bovine immune system and on the severity of metritis (Sordillo, 2013). Moreover, an association between a greater degree of negative energy balance (characterized by elevated prepartum NEFA concentration and postpartum BHBA concentration) and decreased immune response in cows that developed uterine disease compared with healthy cows has been reported (Cai et al., 1994; Kimura et al., 1999; Hammon et al., 2006; Galvão et al., 2010).

Machado et al. (2013) evaluated the effect of injectable trace mineral supplementation (ITMS) in a large multifarm clinical trial that enrolled over 1,400 cows and reported that cows injected with trace minerals at drying off and during the transition period were at significantly lower risk of stillbirth parturition, endometritis, and clinical and subclinical mastitis. Additionally, it was observed that ITMS decreased the presence of $T$. pyogenes and $F$. necrophorum in the uterus at 35 DIM (Machado et al., 2012). Although these studies provided some useful information regarding the potential benefits ITMS might have for transition cows, it also created questions regarding the possible biological mechanisms that led to the observed effects.

Considering the benefits of trace minerals and other minerals to physiological processes, energy metabolism, and immune status, we hypothesized that occurrence of uterine diseases would be associated with mineral levels, energy metabolites, and markers of immune function and supplementation with ITMS would mitigate the negative effects of mineral deficiencies on homeostasis, immune function, and development of diseases. Therefore, the objective of the present study was to evaluate the relationship between selected serum mineral levels, energy metabolites, oxidative stress indicators, IL-8 and haptoglobin levels, and the potential for uterine diseases. Additionally, we investigated the effect of ITMS on metabolism, immune function, and animal health under field conditions involving a dairy herd with high milk production.

\section{MATERIALS AND METHODS}

\section{Farm and Management}

This study was conducted in a dairy farm located near Ithaca, New York. Cows were enrolled from October 3, 2012 until January 10, 2013; the follow-up period continued until July 1, 2013. This farm was selected because of its long working relationship with the Am- bulatory and Production Medicine Clinic at Cornell University. The farm milked 3,300 Holstein cows 3 times daily in a double 52-stall parallel milking parlor. The cows were housed in freestall barns, with concrete stalls covered with mattresses and bedded with manure solids. All cows were offered a TMR consisting of approximately $55 \%$ forage (corn silage, haylage, and wheat straw) and $45 \%$ concentrate (corn meal, soybean meal, canola, cottonseed, and citrus pulp) on a DM basis. The diet was formulated to meet or exceed the NRC nutrient requirements for lactating Holstein cows weighing $650 \mathrm{~kg}$ and producing $45 \mathrm{~kg}$ of $3.5 \% \mathrm{FCM}$ (NRC, 2001). The chemical compositions (mineral and vitamins) of prefresh and lactating cow diets for study farm are presented in Table 1 . The farm reproductive management used a combination of Presynch, Ovsynch, Resynch and detection of estrus, with 25 to $30 \%$ of cows bred via timed AI and the remainder bred after detection of estrus solely by activity monitors (Alpro; DeLaval, Kansas City, MO).

\section{Study Design and Treatments}

A total of 270 cows were enrolled in the study. A complete randomized field trial study design was used; cows were randomly allocated into 1 of 2 treatments groups: ITMS or control. All dry cows that were available during the enrollment period were included in the study (Figure 1). Randomization was completed in Excel (Microsoft, Redmond, WA) using the random number function and imported into the farm's Dairy Comp 305 program (Valley Agricultural Software, Tulare, CA). Cows that were randomly assigned to the treatment group received 2 injections of trace minerals (Multimin North America, Inc., Fort Collins, Co) at 230 and $260 \mathrm{~d}$ of gestation; each injection contained 300 $\mathrm{mg}$ of $\mathrm{Zn}, 50 \mathrm{mg}$ of $\mathrm{Mn}, 25 \mathrm{mg}$ of Se, and $75 \mathrm{mg}$ of $\mathrm{Cu}$. Blood samples were collected from coccygeal vein or artery using a Vacutainer tube without anticoagulant (for serum), a Vacutainer tube with lithium heparin (for plasma), and a 20-gauge $\times 2.54$-cm Vacutainer needle (Becton, Dickinson and Company, Franklin Lakes, NJ). After collection, all blood samples were transported to the laboratory on ice and spun in a centrifuge at $2,000 \times g$ for 15 min at $4^{\circ} \mathrm{C}$, and the serum and plasma were harvested and frozen at $-80^{\circ} \mathrm{C}$. Serum and plasma samples were collected at $230 \pm 3 \mathrm{~d}$ of gestation, 260 $\pm 3 \mathrm{~d}$ of gestation, $274 \pm 3 \mathrm{~d}$ of gestation, $3 \pm 2 \mathrm{DIM}$, $7 \pm 2$ DIM, $14 \pm 2$ DIM, and $25 \pm 3$ DIM. Body condition scores were determined for all study cows at blood collection time by a single investigator blinded to treatment group using a 5 -point scale with a quarterpoint system, as previously described (Edmonson et al., 1989). 
Table 1. Chemical composition (mineral and vitamins) of prefresh and lactating cow diets ${ }^{1}$

\begin{tabular}{|c|c|c|c|c|}
\hline \multirow[b]{2}{*}{ Item } & \multicolumn{2}{|c|}{$\begin{array}{l}\text { NRC (2011) } \\
\text { recommendation }\end{array}$} & \multicolumn{2}{|c|}{ Farm diet } \\
\hline & Prefresh & Lactation & Prefresh & Lactation \\
\hline Calcium (\%) & 0.45 & 0.67 & 1.43 & 0.90 \\
\hline Phosphorus (\%) & 0.23 & 0.36 & 0.42 & 0.39 \\
\hline Magnesium (\%) & 0.12 & 0.2 & 0.45 & 0.32 \\
\hline Potassium (\%) & 0.52 & 1.06 & 1.52 & 1.56 \\
\hline Sodium (\%) & 0.10 & 0.22 & 0.15 & 0.47 \\
\hline Chloride (\%) & 0.15 & 0.28 & 0.44 & 0.77 \\
\hline Sulfur (\%) & 0.20 & 0.20 & 0.49 & 0.26 \\
\hline Copper $(\mathrm{mg} / \mathrm{L})$ & 13.0 & 11.0 & 16.81 & 22.52 \\
\hline Manganese $(\mu \mathrm{g} / \mathrm{L})$ & 18.0 & 13.0 & 96.21 & 65.03 \\
\hline Selenium $(\mu \mathrm{g} / \mathrm{L})$ & 0.30 & 0.30 & 0.45 & 0.70 \\
\hline Zinc $(\mathrm{mg} / \mathrm{L})$ & 22.0 & 52.0 & 66.61 & 84.93 \\
\hline Vitamin A (kIU/d) & 82.6 & 75.0 & 6.36 & 6.58 \\
\hline Vitamin D (kIU/d) & 21.5 & 21.0 & 1.15 & 1.45 \\
\hline Vitamin E (IU/d) & 1,202 & 545 & 56.86 & 32.46 \\
\hline
\end{tabular}

${ }^{1}$ Prefresh diets were fed from 3 wk prepartum through parturition and lactation diets were fed from parturition through wk 35 postpartum.

\section{Case Definitions}

Retained placenta and metritis were diagnosed and treated by trained farm personnel according to specific protocols designed by the Ambulatory and Production Medicine Clinic at Cornell University. Retained placenta was defined as a condition in which cows failed to release their fetal membranes within $24 \mathrm{~h}$ of calving. Puerperal metritis (metritis) was defined as the presence of fetid, watery, red-brown uterine discharge and rectal temperature greater than $39.5^{\circ} \mathrm{C}$. Clinical endometritis evaluation was performed by the investigators at $25 \pm$ 3 DIM, and it was defined as a presence of purulent or mucopurulent discharge, by retrieving vaginal mucus using the Metricheck device (Metricheck, SimcroTech, Hamilton, New Zealand), as described in a previous study (McDougall et al., 2007).

\section{Blood Mineral Analysis}

A random subset of 100 serum samples primarily stored at $-80^{\circ} \mathrm{C}$ were sent to the Veterinary Diagnostic

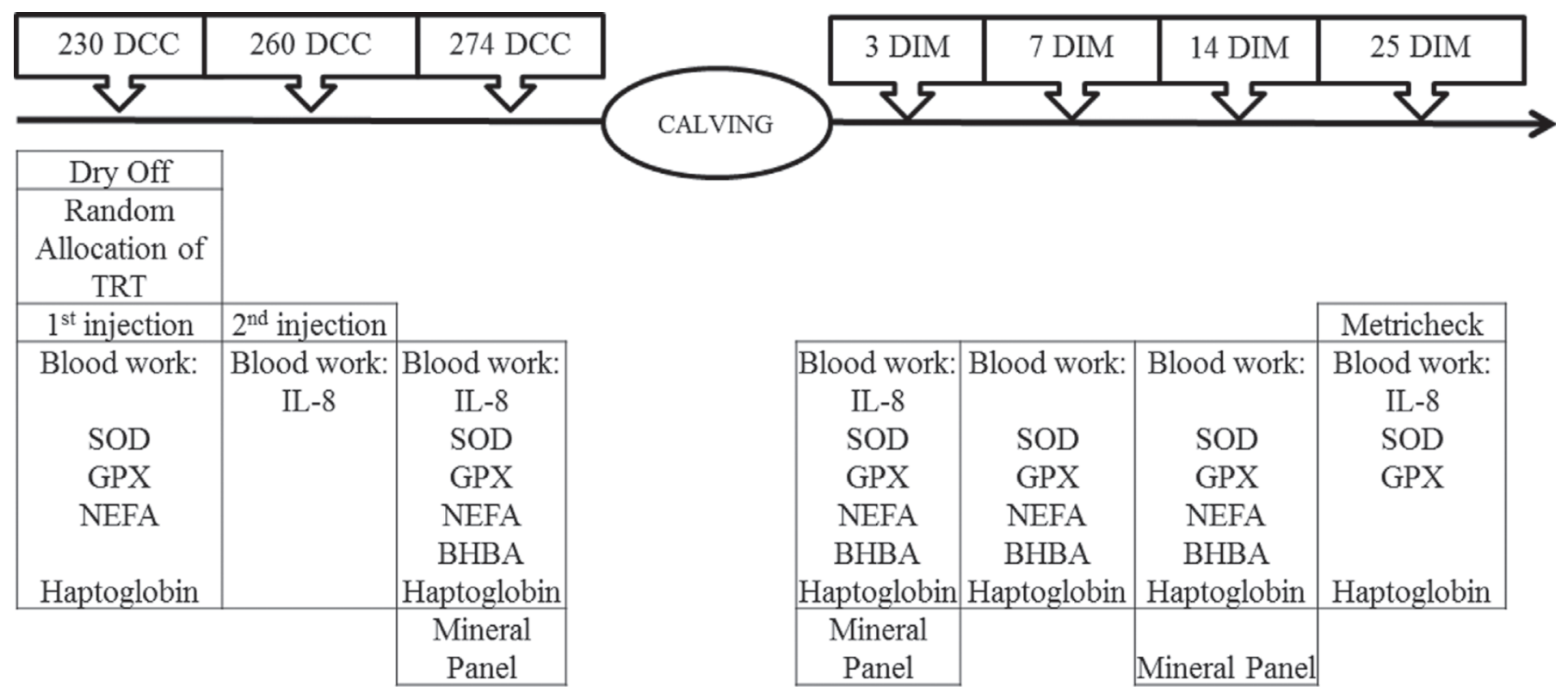

Figure 1. Scheme of the study design. Dry cows $(\mathrm{n}=270)$ were randomly assigned to 2 treatment groups: group 1 [5 mL s.c. injection of trace mineral supplement (ITMS)] and group 2 (control group, saline solution injection). Study cows were subjected to BCS assessment and coccygeal vessels blood collection at each time point. All cows were under the same reproductive program, health, housing, and nutritional management. $\mathrm{GPX}=$ glutathione peroxidase; SOD = superoxide dismutase; TRT = treatment; DCC = days carrying calf. 
Laboratory at Iowa State University (Ames, IA) for analysis of $\mathrm{Mg}$, total phosphorus (Pt), soluble phosphorus (Ps), K, Ca, Fe, Cu, Zn, Se, Mn, and Mo. Blood mineral levels were measured at $274 \pm 3 \mathrm{~d}$ of gestation, $3 \pm 2$ DIM, $7 \pm 2$ DIM, and at $14 \pm 2$ DIM. The concentrations of serum trace elements were analyzed by inductively coupled plasma mass spectrometry system (Varian/Bruker 820 ICP-MS, Bruker Corporation, Fremont, CA) through separation of analyte ions from spectral interferences.

\section{Metabolic and Immune Parameters}

Plasma concentrations of NEFA were analyzed by enzymatic analysis (NEFA-C kit; Wako Pure Chemical Industries, Osaka, Japan). Plasma NEFA concentrations were measured at $230 \pm 3 \mathrm{~d}$ of gestation, 274 $\pm 3 \mathrm{~d}$ of gestation, $3 \pm 2 \mathrm{DIM}, 7 \pm 2 \mathrm{DIM}$, and at $14 \pm 2$ DIM. Serum samples were tested for BHBA concentrations using an electronic BHBA measuring system (Precision Xtra, Abbott, Abingdon, UK) already validated for animal use, with a few changes regarding the experiment (Gordon et al., 2013). Serum BHBA concentrations were measured at $274 \pm 3 \mathrm{~d}$ of gestation, $3 \pm 2$ DIM, $7 \pm 2$ DIM, and at $14 \pm 2$ DIM.

The IL- 8 concentrations of plasma samples were determined using a human IL-8 ELISA kit (R\&D Systems Inc., Minneapolis, MN) validated for use in cattle (Shuster et al., 1996; Galligan and Coomber, 2000). Plasma IL-8 concentrations were measured at $260 \pm 3$ d of gestation, $274 \pm 3 \mathrm{~d}$ of gestation, $3 \pm 2$ DIM, and at $25 \pm 3$ DIM.

Haptoglobin concentration was determined using a colorimetric procedure that measures haptoglobinhemoglobin complex by estimated differences in peroxidase activity. Briefly, $5 \mu \mathrm{L}$ of plasma or distillated water (for blank determination) were added to $7.5 \mathrm{~mL}$ of O-dianisidine solution $(0.6 \mathrm{~g} / \mathrm{L}$ of O-dianisidine, $0.5 \mathrm{~g} / \mathrm{L}$ of EDTA, and $13.8 \mathrm{~g} / \mathrm{L}$ of sodium phosphate monobasic in distilled water; $\mathrm{pH}$ adjusted to 4.1 ) in a borosilicate tube. Twenty-five microliters of a hemoglobin solution $(0.3 \mathrm{~g} / \mathrm{L}$ of bovine hemoglobin in distilled water) was immediately added to each tube. All tubes were incubated in a water bath set at $37^{\circ} \mathrm{C}$ for $45 \mathrm{~min}$. After incubation, $100 \mu \mathrm{L}$ of a freshly prepared working concentration of $156 \mathrm{mM}$ hydrogen peroxide solution was added to each tube. All tubes were incubated for $1 \mathrm{~h}$ at room temperature. After incubation, $200 \mu \mathrm{L}$ of each tube was transferred into one well in a 96-well polystyrene flat-bottom microplate, and optical density (OD) was immediately read at $450 \mathrm{~nm}$ in a microplate reader (BioTek Instruments, Model EL 340, Winooski, VT). The OD from the blank sample was subtracted from the OD of all plasma-containing samples. Results were reported as optical density readings at $450 \mathrm{~nm}$ of wavelength, given that the method used does not contain a standard curve. The absolute absorbance values were used for the statistical analysis. Haptoglobin concentration was measured at $230 \pm 3 \mathrm{~d}$ of gestation, $274 \pm 3$ d of gestation, $3 \pm 2$ DIM, $7 \pm 2$ DIM, $14 \pm 2$ DIM, and at $25 \pm 3$ DIM.

\section{Superoxide Dismutase and Glutathione Peroxidase Activity}

Serum superoxide dismutase (SOD) activity was assessed using Superoxide Dismutase Assay Kit (Cayman Chemical Company, Ann Arbor, MI), following the manufacturer's instructions. Plasma glutathione peroxidase (GPx) activity was assessed using Glutathione Peroxidase Assay Kit (Cayman Chemicals; catalog number 703102) following the manufacturer's instructions. Serum SOD activity and plasma GPx were measured at $230 \pm 3 \mathrm{~d}$ of gestation, $274 \pm 3 \mathrm{~d}$ of gestation, $3 \pm 2$ DIM, $7 \pm 2$ DIM, $14 \pm 2$ DIM, and at $25 \pm 3$ DIM.

\section{Statistical Analysis}

To facilitate data analysis and interpretation, the variable $\mathrm{BCS}$ was categorized into a 3-level variable: 1 if $\mathrm{BCS}$ at enrollment was equal or less than $2.75,2$ if BCS at enrollment was greater than 2.75 and equal or less than 3.25, and 3 if BCS at enrollment was greater than 3.25. Descriptive statistics analysis was undertaken in SAS using the FREQ and UNIVARIATE procedures (SAS Institute Inc., Cary, NC).

Four groups of mixed general linear models were fitted to the data using the MIXED procedure of SAS. For the first, second, third, and fourth group of mixed general linear models, the independent variables of interest were ITMS, RP, metritis, and endometritis, respectively. The dependent variables evaluated in these models were blood mineral concentrations, SOD activity, GPx activity, NEFA, BHBA, IL-8, and haptoglobin. One model was fitted for each dependent variable. The data were longitudinally collected and comprised a series of repeated measures of the dependent variable throughout the time points of each blood parameter measured. Visual evaluation of the distribution plot of the studentized residuals allowed us to assume that the residuals were normally distributed. This implies that data points were correlated within each research subject. To account appropriately for within-cow correlation, the error term was modeled by imposing a first-order autoregressive covariance structure for all statistical models. The model described below was fitted to all mixed general linear models: 


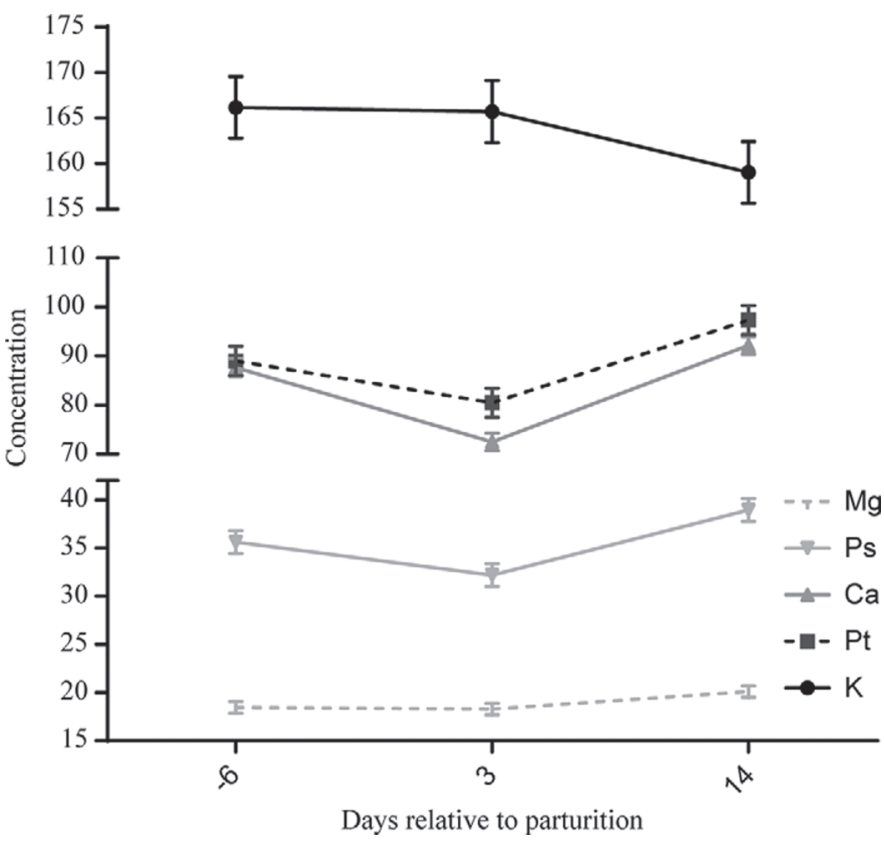

Figure 2. Serum plasmatic concentration of $\mathrm{Ca}(\mathrm{mg} / \mathrm{L}), \mathrm{K}(\mathrm{mg} / \mathrm{L})$, $\mathrm{Mg}(\mathrm{mg} / \mathrm{L}$ ), soluble phosphorus (Ps; mg/L) and total phosphorus (Pt; $\mathrm{mg} / \mathrm{L}$ ) according to days relative to parturition for all cows enrolled in the study. Error bars represent the SEM.

$$
\mathrm{Y}=\mathbf{X} \boldsymbol{\beta}+e,
$$

where $\mathrm{Y}=$ blood mineral levels, serum levels of SOD activity, GPx activity, NEFA, BHBA, IL-8, and haptoglobin; $\mathbf{X}=$ the matrix of all independent variables; $\boldsymbol{\beta}=$ the vector of all fixed effect parameters; and $e=$ random residual.

For all models, the within-cow correlation was accounted for by imposing a first-order autoregressive covariance structure (which assumed that the within-cow correlation of the repeated measures of the dependent variables decreased as the time between the test dates increased) to the error term. The independent variables offered to the models were variable of interest (ITMS, RP, metritis, and endometritis), BCS, parity, and time of each blood parameter was measured. Two-way interactions term between variable of interest and time of blood parameter measurement were offered to the models. Furthermore, interaction terms that had $P$-value $<0.10$ were illustrated in Figures 2, 3, and 4.

\section{RESULTS}

\section{Descriptive Statistics}

A total of 270 cows were used in the final data analysis, of which $119(44.1 \%)$ were primiparous and 151 $(55.9 \%)$ were multiparous. The overall incidences of
$\mathrm{RP}$, metritis, and clinical endometritis were 10.4, 15.2, and $17.0 \%$, respectively.

Control cows had at enrollment an average parity of $1.8(\mathrm{SD}= \pm 1.02)$, BCS of $3.2(\mathrm{SD}= \pm 0.40)$, and carried calves for $224.9 \mathrm{~d}$ ( $\mathrm{SD}= \pm 3.02)$, whereas cows at ITMS treatment had an average parity of $1.9(\mathrm{SD}=$ $\pm 1.01)$, BCS of $3.2(\mathrm{SD}= \pm 0.39)$, and carried calves at enrollment for $224.9 \mathrm{~d}(\mathrm{SD}= \pm 2.80)$. The variation of serum concentration of minerals according to the day relative to parturition is depicted in Figures 2 and 3 . The variation of serum concentration of minerals BHBA, NEFA, haptoglobin, IL-8, and GPx and SOD activity according to the day relative to parturition is shown in Figure 4.

\section{Effects of ITMS on Serum Concentration of Minerals}

Cows supplemented with ITMS had increased serum concentration of $\mathrm{Cu}(P=0.04)$, Se $(P<0.01)$, and $\mathrm{Zn}$ $(P=0.04)$ in comparison with control cows (Table 2$)$. Additionally, ITMS treatment tended to increase serum concentrations of Fe $(P=0.07)$, Ps $(P=0.08)$, and Pt $(P=0.08)$, as depicted in Table 2 . However, no differences in serum concentration of $\mathrm{Ca}(P=0.79), \mathrm{Mg}(P$ $=0.47), \mathrm{K}(P=0.23)$, and Mo $(P=0.22)$ occurred between treatments (Table 2 ). The serum concentra-

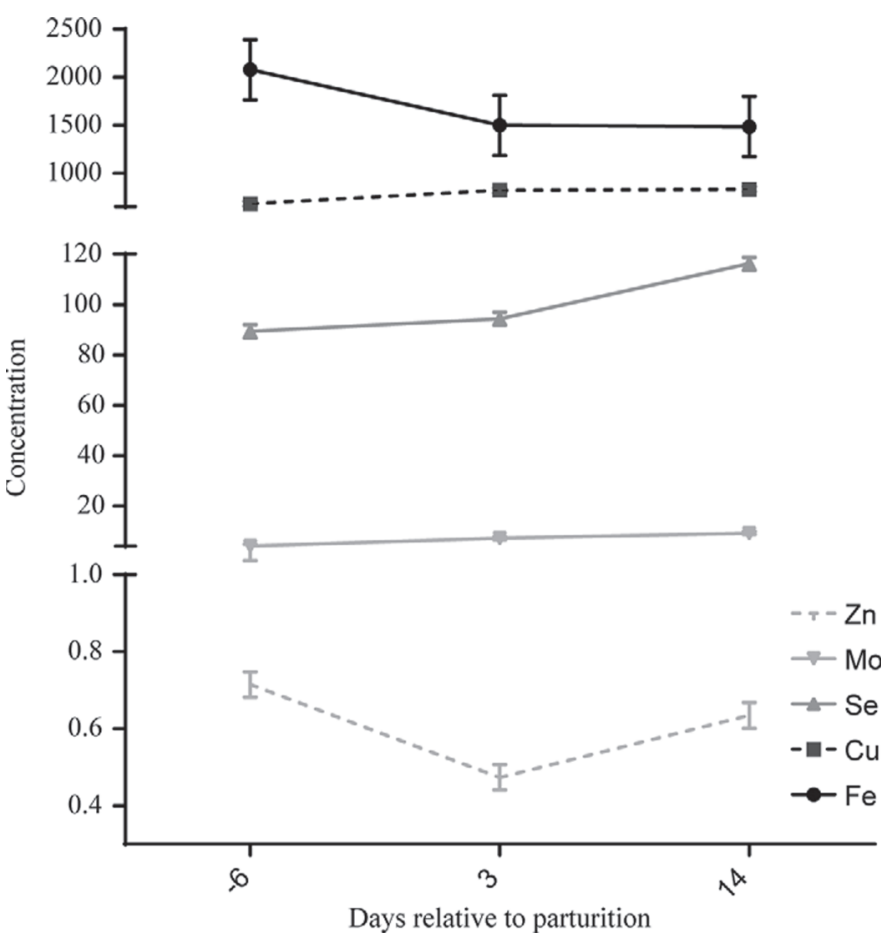

Figure 3. Serum plasmatic concentration of $\mathrm{Cu}(\mathrm{mg} / \mathrm{L}), \mathrm{Fe}(\mu \mathrm{g} / \mathrm{L})$, Mo $(\mu \mathrm{g} / \mathrm{L})$, Se $(\mu \mathrm{g} / \mathrm{L})$, and $\mathrm{Zn}(\mu \mathrm{g} / \mathrm{L})$ according to days relative to parturition for all cows enrolled in the study. Error bars represent the SEM. 


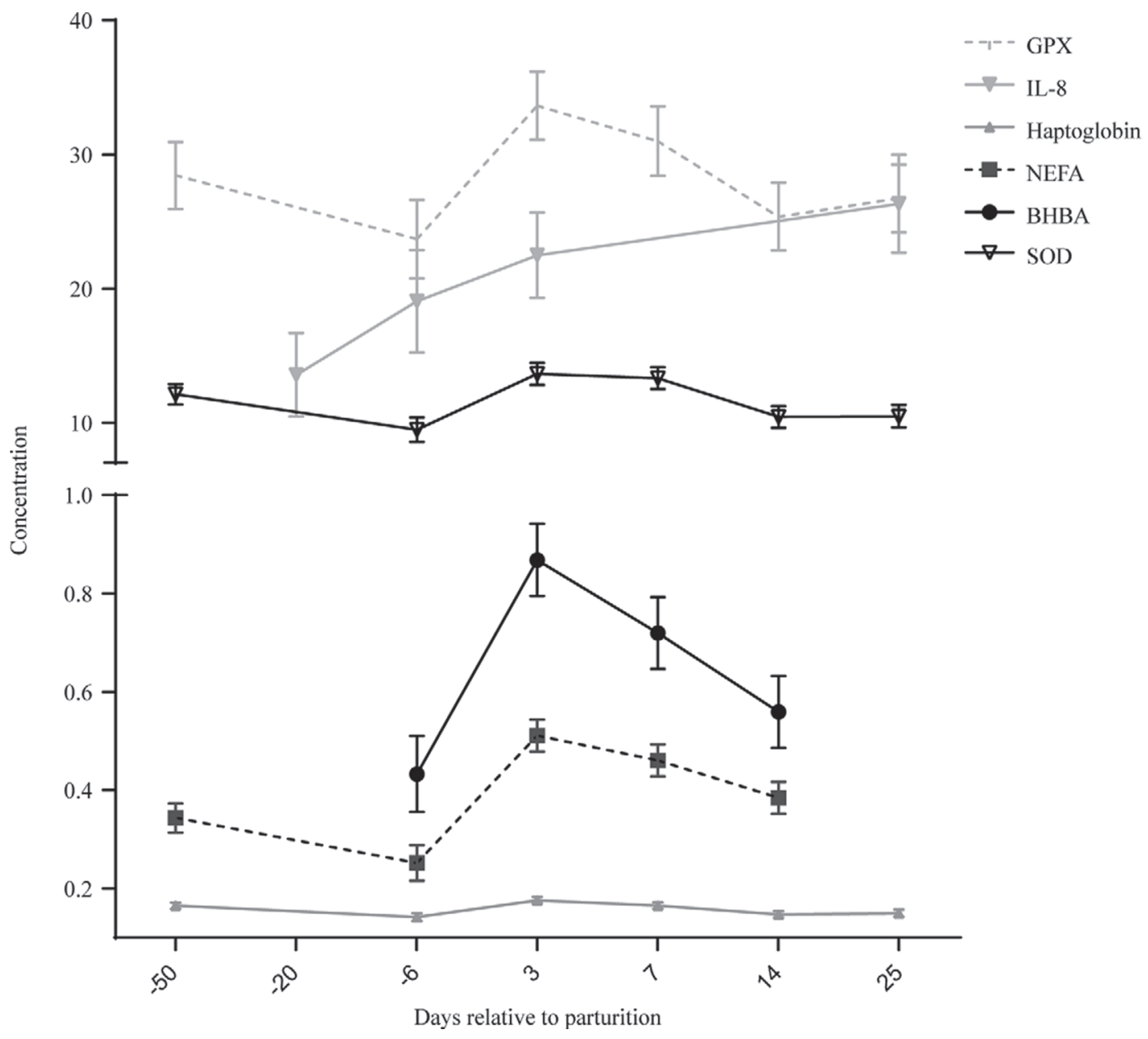

Figure 4. Serum plasmatic concentration of BHBA (mmol/L), NEFA (mEq/L), haptoglobin (optical density units), IL-8 (pg/mL), and activities of glutathione peroxidase (GPX; nmol/min per milliliter) and superoxide dismutase (SOD; U/mL) according to days relative to parturition for all cows enrolled in the study. Error bars represent the SEM.

tion of $\mathrm{Ca}, \mathrm{Cu}, \mathrm{K}, \mathrm{Mg}, \mathrm{Mo}, \mathrm{Ps}, \mathrm{Pt}$, Se, and $\mathrm{Zn}$ varied $(P<0.01)$ according to days relative to parturition following the same pattern present in Figures 2 and 3. Serum concentration of Fe was not different $(P=0.14)$ according to time relative to parturition. Moreover, no interactions were observed between treatment and time for concentration of serum minerals (Table 2).

\section{Effects of ITMS on Metabolic, Immune, and Oxidative Stress Parameters}

Supplementation with trace minerals did not affect plasma concentration of BHBA $(P=0.99$, Table 2$)$. Plasma NEFA concentration was marginally increased $(P=0.05)$ in ITMS cows when compared with control cows (Table 2). No interactions were noted between treatment and time for BHBA and NEFA (Table 2). Cows supplemented with trace minerals prepartum had no differences on concentration of IL-8 $(P=0.72)$, haptoglobin $(P=0.18)$, and activity of $\operatorname{GPx}(P=0.67)$ and $\operatorname{SOD}(P=0.58)$ when compared with control cows (Table 2). Additionally, no interactions were observed between treatment and time for metabolic, immune, and oxidative stress parameters (Table 2).

\section{Association Between RP and Serum Concentration of Minerals}

Cows with RP had reduced serum concentrations of Ca $(P<0.01), \operatorname{Mg}(P<0.01)$, Mo $(P=0.03)$, and Zn $(P<0.01)$ when compared with cows without RP (Table 3). Conversely, no differences on serum concentrations of $\mathrm{Cu}(P=0.83), \mathrm{Fe}(P=0.46), \mathrm{K}(P=$ $0.16)$, Ps $(P=0.13)$, Pt $(P=0.13)$, and Se $(P=0.34)$ occurred between affected or nonaffected cows (Table $3)$. Tendencies for interactions between occurrence of $\mathrm{RP}$ and time for $\operatorname{Ps}(P=0.08)$ and $\operatorname{Pt}(P=0.09)$ were noted, as shown in Table 3. Cows without RP tended to have increased serum concentration of $\mathrm{Ps}$ and $\mathrm{Pt}$ at d 14 postpartum, whereas cows having RP had no 
Table 2. Effect of injectable trace mineral supplementation (ITMS) on serum concentration of minerals, BHBA, NEFA, haptoglobin, IL-8, glutathione peroxidase, and superoxide dismutase

\begin{tabular}{|c|c|c|c|c|c|}
\hline \multirow[b]{2}{*}{ Outcome variable } & \multicolumn{2}{|c|}{ Treatment } & \multicolumn{3}{|c|}{$P$-value } \\
\hline & Control & ITMS & $\mathrm{TRT}^{1}$ & Time & $\mathrm{TRT} \times$ time \\
\hline 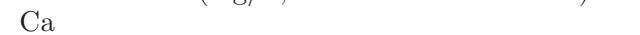 & 85.68 & 85.41 & 0.79 & $<0.01$ & 0.42 \\
\hline $\mathrm{Cu}$ & 0.76 & 0.79 & 0.04 & $<0.01$ & 0.61 \\
\hline $\mathrm{Fe}$ & 1.65 & 1.97 & 0.07 & 0.14 & 0.12 \\
\hline $\mathrm{K}$ & 163.23 & 165.51 & 0.23 & $<0.01$ & 0.58 \\
\hline $\mathrm{Ps}^{2}$ & 36.62 & 37.80 & 0.08 & $<0.01$ & 0.86 \\
\hline $\mathrm{Pt}^{3}$ & 91.58 & 94.51 & 0.08 & $<0.01$ & 0.86 \\
\hline $\operatorname{Se}(\mu \mathrm{g} / \mathrm{L})$ & 101.79 & 106.29 & $<0.01$ & $<0.01$ & 0.58 \\
\hline $\mathrm{Zn}(\mu \mathrm{g} / \mathrm{L})$ & 0.58 & 0.62 & 0.04 & $<0.01$ & 0.61 \\
\hline \multicolumn{6}{|l|}{ Metabolic, immune, and oxidative stress parameter } \\
\hline $\operatorname{BHBA}(\mathrm{mmol} / \mathrm{L})$ & 0.63 & 0.62 & 0.99 & $<0.01$ & 0.55 \\
\hline NEFA $(\mathrm{mEq} / \mathrm{L})$ & 0.38 & 0.40 & 0.05 & $<0.01$ & 1.00 \\
\hline
\end{tabular}

${ }^{1}$ TRT $=$ treatment

${ }^{2} \mathrm{Ps}=$ soluble phosphorus.

${ }^{3} \mathrm{Pt}=$ total phosphorus.

differences in Ps and Pt serum concentration at $14 \mathrm{~d}$ after parturition (Figure 5).

\section{Association Between RP and Metabolic, Immune, and Oxidative Stress Parameters}

Cows with RP had no differences in concentrations of BHBA $(P=0.53)$ and NEFA $(P=0.53)$ when compared with cows not having RP (Table 3). An in- teraction was observed between occurrence of RP and time postpartum for concentration of $\operatorname{BHBA}(P=0.02$, Table 3). Cows diagnosed with RP had an increased concentration of BHBA at d 3 postpartum, but cows without RP had no variations in BHBA concentration on d 3 postpartum (Figure 5). Cows affected with RP tended $(P=0.09)$ to have a higher concentration of IL-8 than their counterparts not diagnosed with RP (Table 3). Cows with and without RP had no differ-

Table 3. Association of retained placenta (RP) and serum mineral concentration, BHBA, NEFA, haptoglobin, IL-8, glutathione peroxidase, and superoxide dismutase

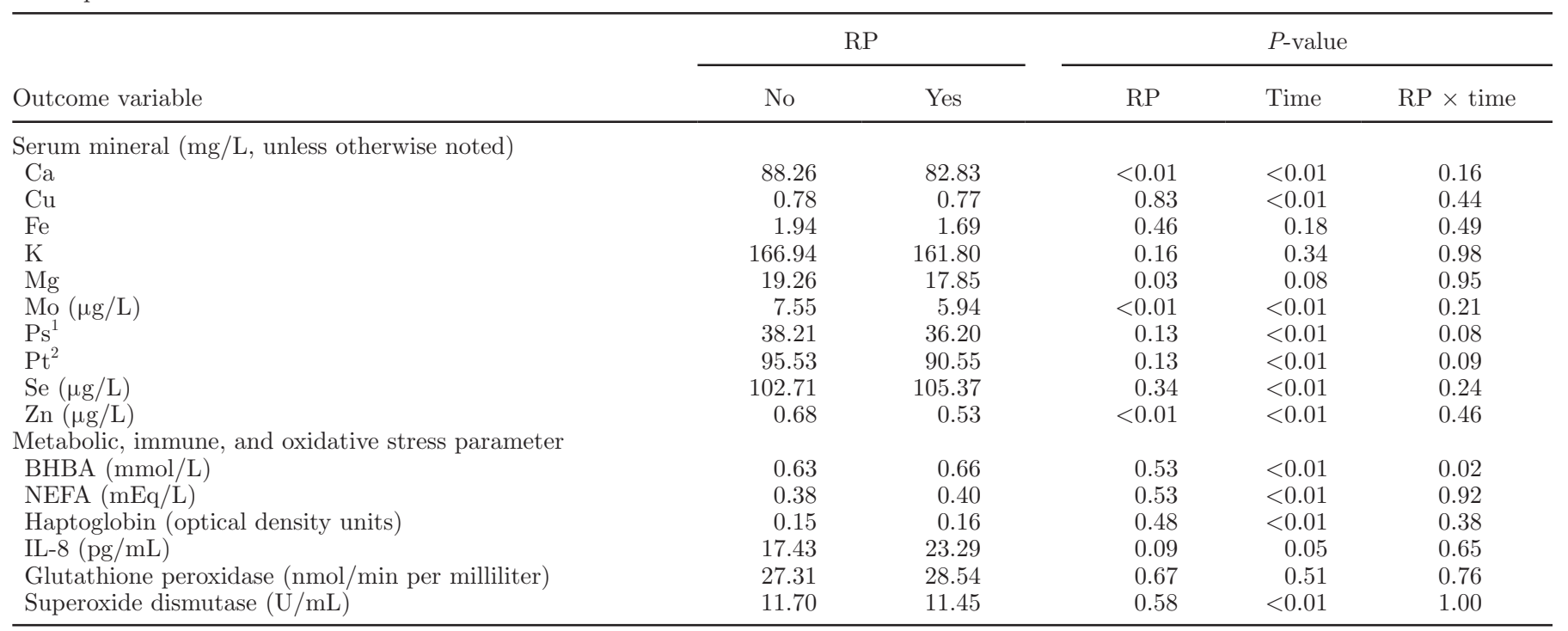

${ }^{1} \mathrm{Ps}=$ soluble phosphorus.

${ }^{2} \mathrm{Pt}=$ total phosphorus. 

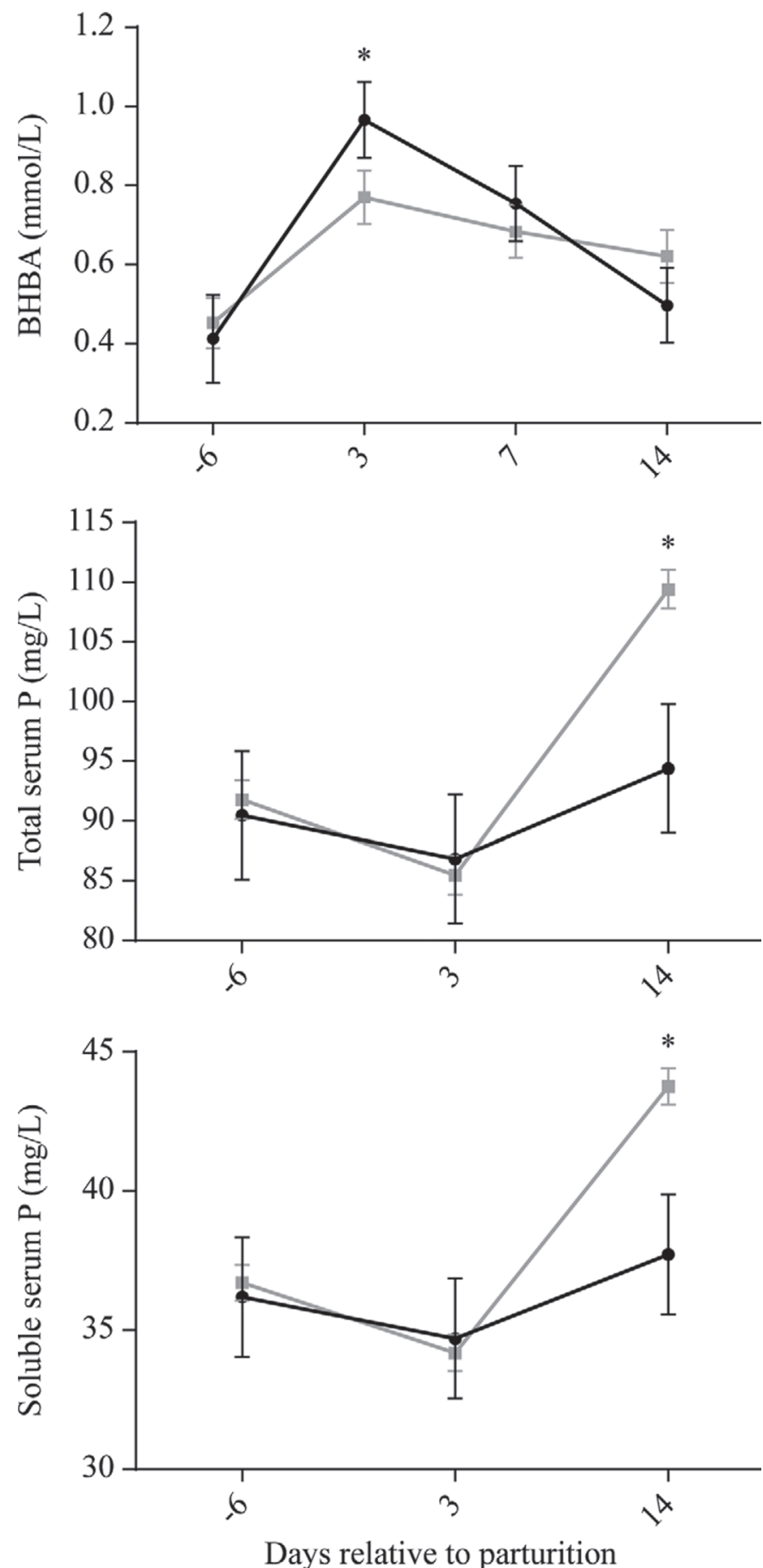

Figure 5. Association between occurrence of retained placenta and day relative to parturition for $\mathrm{BHBA}$, total $\mathrm{P}$, and soluble $\mathrm{P}$. The $\mathrm{y}-$ axis represents the LSM in all graphics. Error bars represent the $95 \%$ CI for group means. Cows with retained placenta are represented by a black line, and cows that did not have their retained placenta are depicted by a gray line; an asterisk $(*)$ represents $P<0.05$.

ences on concentration of haptoglobin $(P=0.48)$ and activity of $\operatorname{GPx}(P=0.67)$ and $\operatorname{SOD}(P=0.58)$, as shown in Table 3. Additionally, no interactions were noted between occurrence of RP and time for other metabolic, immune, and oxidative stress parameters (Table 3).

\section{Association Between Metritis and Serum Concentration of Minerals}

Cows affected with metritis had significantly lower serum concentrations of $\mathrm{Ca}(P<0.01)$, Mo $(P=0.03)$, $\mathrm{Ps}(P<0.01)$, Pt $(P<0.01)$, Se $(P=0.02)$, and $\mathrm{Zn}$ $(P<0.01)$ than counterparts without metritis (Table 4). Additionally, metritic cows tended to have lower concentration of $\mathrm{K}(P=0.09)$ when compared with nonmetritic cows. Moreover, no differences on serum concentrations of $\mathrm{Cu}(P=0.85)$, Fe $(P=0.14)$, and $\mathrm{Mg}(P=0.46)$ were identified between metritic and nonmetric cows (Table 4). Tendencies were noted for interactions between occurrence of metritis and time for Ps $(P=0.07)$ and $\mathrm{Pt}(P=0.07$; Table 4$)$. Cows with metritis had reduced serum concentration of $\mathrm{Zn}$ at $\mathrm{d} 3$ postpartum, but cows without metritis had no differences in serum concentration of $\mathrm{Zn}$ at $\mathrm{d} 3$ postpartum (Figure 6). Additionally, cows without metritis tended to have increased serum concentration of Ps and $\mathrm{Pt}$ at d 14 postpartum, whereas cows with metritis had no differences in Ps and Pt serum concentration at d 14 after parturition (Figure 6).

\section{Association Between Metritis and Metabolic, Immune, and Oxidative Stress Parameters}

Serum concentration of BHBA did not differ $(P=$ 0.22 ) between metritic and nonmetritic cows (Table 4 ). Cows diagnosed with metritis tended to have a reduced concentration of NEFA $(P=0.09)$ in comparison with cows without metritis (Table 4). Haptoglobin concentration was higher for metritic cows $(P<0.01)$ than for nonmetritic cows (Table 4). An interaction between occurrence of metritis and time relative to parturition for concentration of haptoglobin $(P=0.02$, Table 4$)$ was observed. The haptoglobin levels of metritic cows increased significantly on d 3 and 7 after parturition; this was not the case for cows without metritis (Figure 6). Concentration of IL-8 and activities of GPx and SOD did not differ between metritic and nonmetritic cows (Table 4).

\section{Association Between Endometritis and Serum Concentration of Minerals}

Serum concentration of $\mathrm{Ca}(P<0.01), \mathrm{Cu}(P=0.04)$, Mo $(P<0.01)$, and $\mathrm{Zn}(P<0.01)$ were reduced in cows diagnosed with endometritis in comparison with cows without endometritis (Table 5). Additionally, cows with endometritis tended to have lower serum concen- 
Table 4. Association between metritis and serum mineral concentration, BHBA, NEFA, haptoglobin, IL-8, glutathione peroxidase, and superoxide dismutase

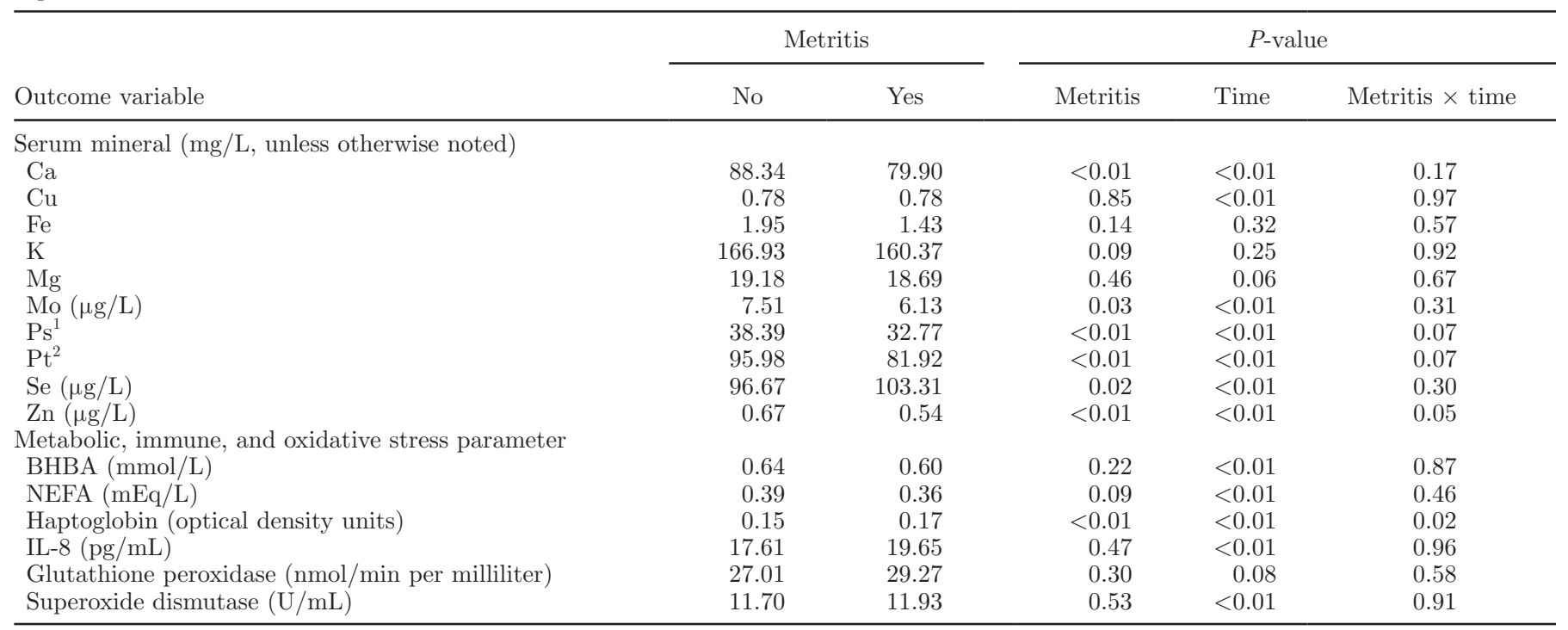

${ }^{1} \mathrm{Ps}=$ soluble phosphorus.

${ }^{2} \mathrm{Pt}=$ total phosphorus.

trations of Ps $(P=0.07)$, Pt $(P=0.07)$, and Se $(P$ $=0.06)$ than their counterparts without endometritis (Table 5). Moreover, no differences in concentration of Fe $(P=0.26), \mathrm{K}(P=0.29)$, and $\mathrm{Mg}(P=0.55)$ occurred between endometritic and nonendometritic cows (Table 5). Interactions were noted between the occurrence of endometritis and time for Ps $(P=0.03)$, $\mathrm{Pt}(P=0.03)$, and $\mathrm{Zn}(P=0.05)$ serum concentrations (Table 5). Furthermore, tendencies for interactions were observed between the occurrence of endometritis and time for Ca $(P=0.08)$ and Se $(P=0.06)$ serum concentrations (Table 5). The serum concentrations of $\mathrm{Ca}$ and $\mathrm{Zn}$ reduced in cows with endometritis at $\mathrm{d}$ 3 postpartum, but not in cows without endometritis (Figure 7). Additionally, cows without endometritis had increased serum concentration of Ps, Pt, and Se at d 14 postpartum, but cows with endometritis had no differences in Ps, Pt, and Se serum concentrations at d 14 after parturition (Figure 7).

\section{Association Between Endometritis and Metabolic, Immune, and Oxidative Stress Parameters}

No variations were seen on serum concentrations of BHBA $(P=0.86)$ and NEFA $(P=0.99)$ for cows with or without endometritis (Table 5). The haptoglobin levels of endometritic cows were reduced $(P<0.01)$ when compared with cows without endometritis (Table 5). Cows diagnosed with endometritis also had increased $(P=0.01)$ concentration of IL-8 when compared with cows without endometritis (Table 5). The activities of
GPx and SOD did not differ between cows with and without endometritis (Table 5). An interaction $(P=$ 0.02 ) between occurrence of endometritis and time for the levels of haptoglobin was observed (Table 5). The haptoglobin levels of endometritic cows increased significantly on d 3 and 7 after parturition, which was not observed in cows without endometritis (Figure 7).

\section{DISCUSSION}

The present study was designed in an attempt to elucidate the physiological mechanisms that could explain results previously reported by our group (Machado et al. 2013). We reported herein that ITMS resulted in a significant increase in the serum levels of $\mathrm{Cu}, \mathrm{Se}$, and Zn during the study period. Unfortunately, Mn concentrations were below detectable levels in all our samples, so we were unable to determine the effect of ITMS on Mn. Our results are in agreement with Pogge et al. (2012), who reported that the serum concentration of $\mathrm{Zn}$ and liver concentration of $\mathrm{Cu}$ and Se was increased in steers after ITMS for at least a 15-d period (Pogge et al., 2012). In the present study, ITMS was not significantly associated with energy metabolites, oxidative stress indicators, and serum concentrations of IL-8 and haptoglobin. Nevertheless, treatment significantly increased the serum levels of $\mathrm{Cu}, \mathrm{Zn}$, and Se. Cows diagnosed with metritis, were found to be significantly deficient in $\mathrm{Zn}$ and Se; endometritic cows had significantly lower concentrations of $\mathrm{Zn}$ and $\mathrm{Cu}$, and cows with RP were found to be significantly deficient in $\mathrm{Zn}$ 

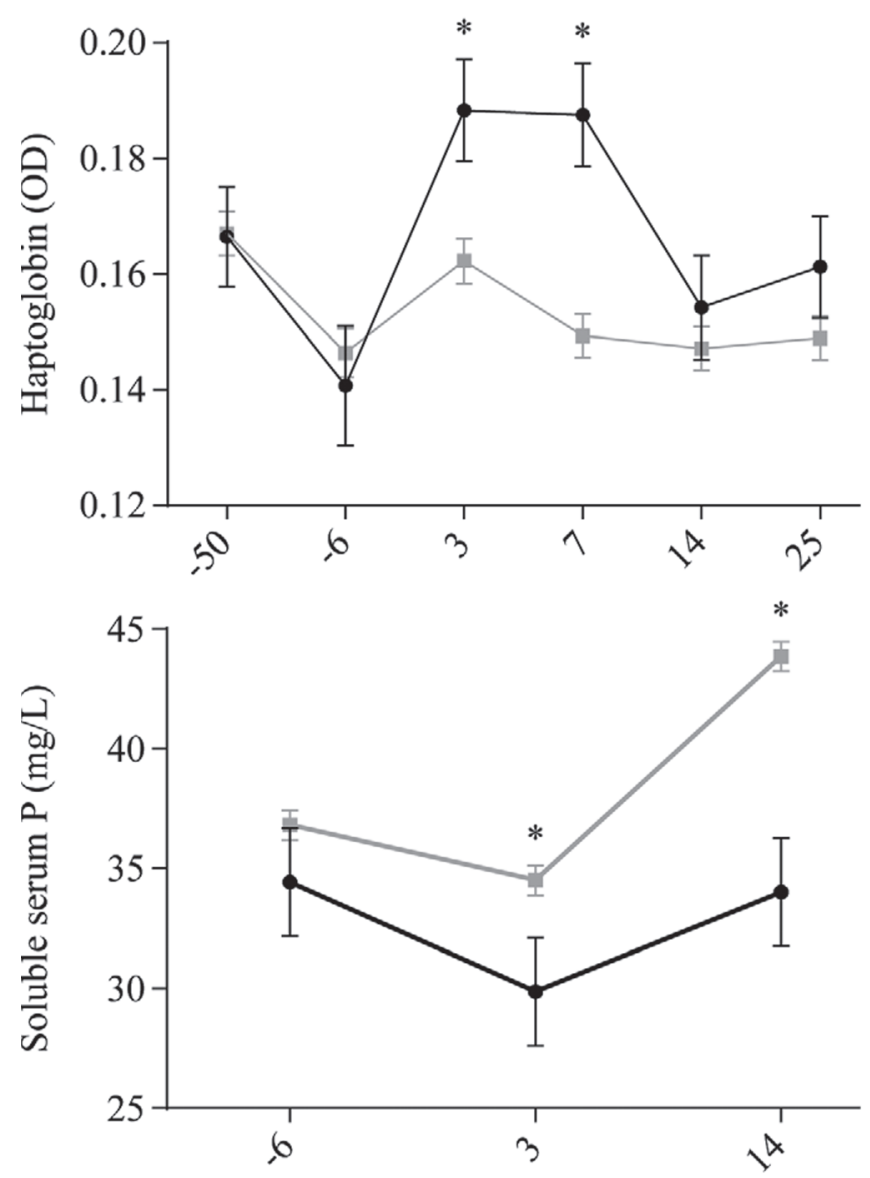

Days relative to parturition
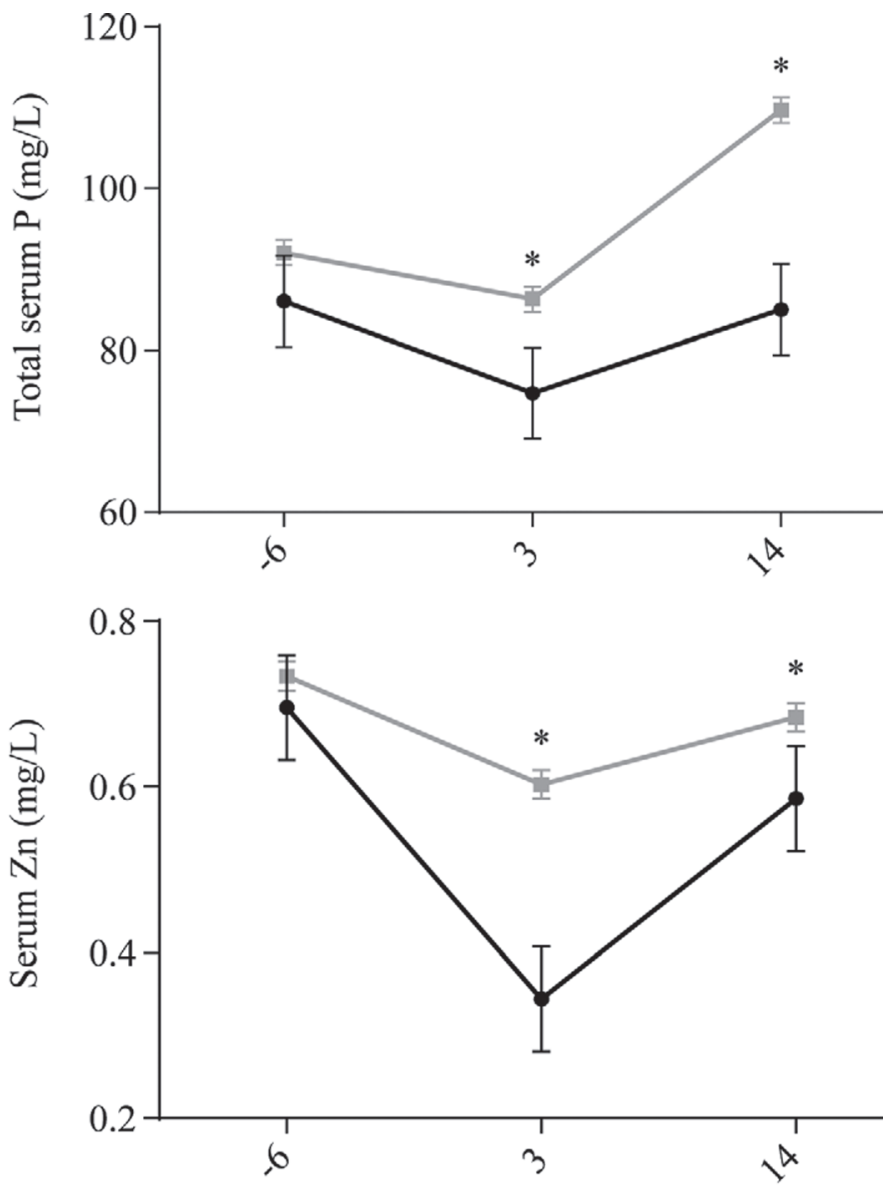

Days relative to parturition

Figure 6. Association between the occurrence of metritis and day relative to parturition for haptoglobin (optical density units), total P, soluble $\mathrm{P}$, and $\mathrm{Zn}$. The y-axis represents the LSM \pm SEM in all graphics. Error bars represent the $95 \%$ CI for group means. Cows with metritis are represented by a black line, and cows that did not have metritis are depicted by a gray line; an asterisk $(*)$ represents $P<0.05$. OD $=$ optical density.

in comparison to healthy herdmates. Therefore, it is possible to suggest that trace minerals, particularly $\mathrm{Cu}$, $\mathrm{Zn}$, and Se, might improve the health of postpartum cows through mechanisms other than the ones evaluated in the present study.

Although the pre- and postpartum diets were formulated according to NRC requirements, several issues preclude the validity of the current established trace mineral requirements in diets. The model of calculation for trace minerals requirements was based on a response system rather than a nutrient requirement model. Therefore, this system information is from studies in which graded amounts of a nutrient were fed, different responses were measured, and the amount or concentration that leads to the optimal response was set as the requirement (Weiss, 2005). The critical issues with this approach are identification of the correct response variable or variables, which can be very difficult and imprecise, and defining the optimal response is also difficult and arbitrary; likewise, variation in bioavailability of the trace mineral among feedstuffs is not usually considered (Weiss, 2005). Thus, quantifying the requirements of dairy cattle for trace minerals precisely is a particularly difficult task. Trace minerals are needed in minute amounts, but variation in feed composition and DMI can be high, making precise and accurate measurements of intake of trace minerals difficult. Many trace minerals can be stored in various body tissues (especially the liver), which means that experimental diets may have to be fed for several months before body stores equilibrate with dietary intake (Weiss, 2005).

Trace minerals are essential to multiple biochemical processes, including immune response, cell replication, skeletal development, and reproductive performance (Underwood and Suttle, 1999). Whole blood Se concentrations have been positively correlated with neutrophil adhesion (Cebra et al., 2003), as well as neutrophil and 
Table 5. Association between endometritis and mineral profile, haptoglobin, BHBA, NEFA, superoxide dismutase, and glutathione peroxidase

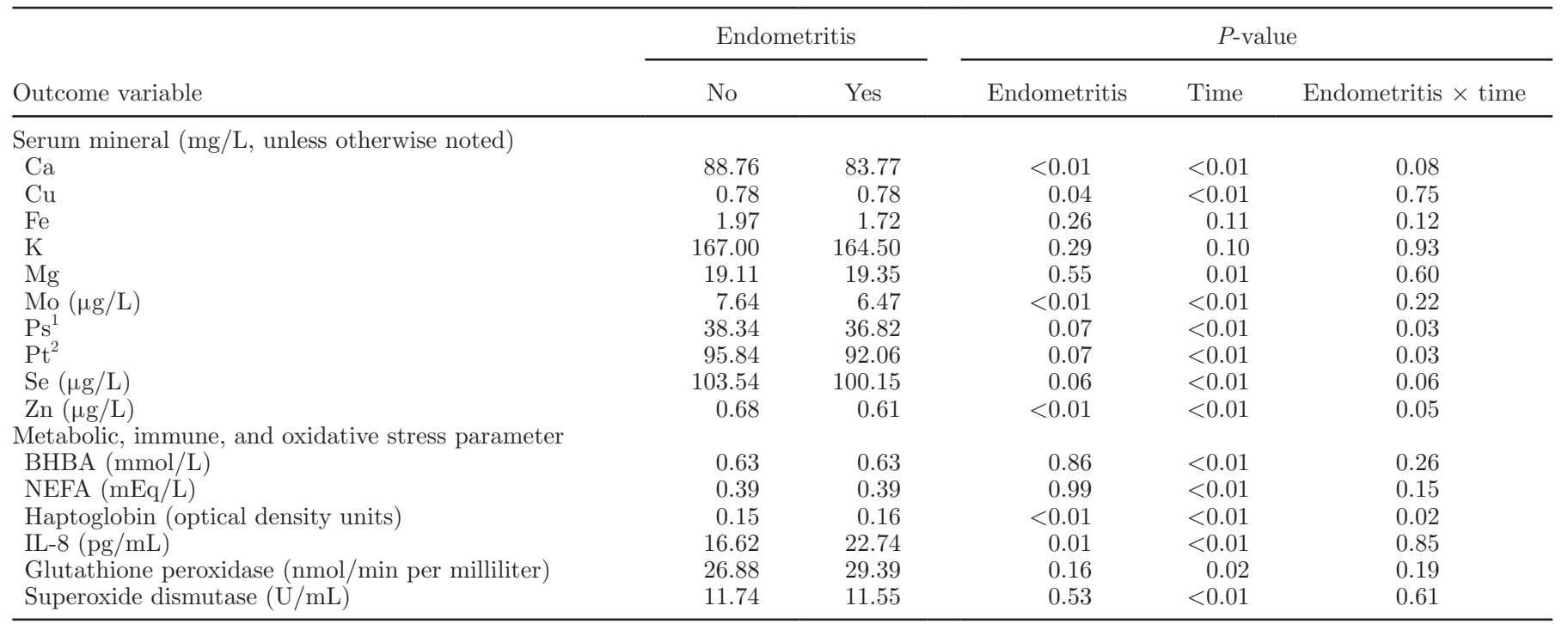

${ }^{1} \mathrm{Ps}=$ soluble phosphorus.

${ }^{2} \mathrm{Pt}=$ total phosphorus.

macrophages migration and killing ability (Ndiweni and Finch, 1995); $\mathrm{Cu}$ is known to affect phagocytic and specific immune functions (Spears and Weiss, 2008). Zinc has long been recognized as an important nutrient for spermatogenesis and male fertility in farm animals, whereas $\mathrm{Zn}$ deficiencies have been linked to immunity impairment and lower disease resistance (Shankar and Prasad, 1998). Therefore, the positive effects of mineral supplementation found in our study could perhaps be associated with mineral action on the immune response and cellular enzymatic activities, including hormone production; these parameters were not evaluated in the current study.

Some positive effects of such supplementation on cow reproductive traits have already been shown. Harrison et al. (1984) reported a decrease in uterine disorders during the early postpartum period when prepartum Se injections were administered. Sales et al. (2011) described an increase in the conception rate of heifers that received trace minerals subcutaneously $17 \mathrm{~d}$ before embryo transfer. A possible explanation for these results could be that ITMS could have improved the transition cows' immune response, either having a direct effect on their immune system or through improving liver function and the cows' adaptation to the negative energy balance period.

It has been suggested that periparturient immunosuppression and energy status is associated with increased susceptibility to infection around calving. In addition, an in vitro study performed by Contreras et al. (2012), revealed that bovine endothelial cells, when exposed to NEFA concentrations emulating the differ- ent degrees of lipid mobilization, as observed during the transition period, presented upregulation of the $I L-8$ gene. In addition, Galvão et al. (2010) reported an increased endometrial expression of the $I L-8$ gene in cows with endometritis and with a greater degree of negative energy balance. In the present study, circulating cytokine (IL-8) concentrations tended to be higher in endometritic cows and in cows with RP, even though NEFA levels were not statistically different among affected and unaffected cows.

Elevated NEFA concentration is detrimental to liver cells and may lead to increased haptoglobin concentrations (Katoh, 2002). Even though metritic cows in our study did not have high NEFA levels, cows that did develop metritis presented significantly higher levels of haptoglobin concentrations during first week after parturition compared with healthy cows. Metritis is an inflammatory condition, and therefore elevated levels of an acute phase protein are expected (Lomborg et al., 2008). Our results support other studies that found an association between elevated haptoglobin in the postpartum period and metritis (Sheldon et al., 2001; Dubuc et al., 2010). Haptoglobin plasma concentrations after parturition were also found to be higher in cows that had endometritis than in cows without endometritis. However, inflammation in the early postpartum period, likely from a metritic uterus, may be associated with greater odds of maintaining endometrial, cervical, or vaginal inflammation. Moreover, haptoglobin concentrations in cows diagnosed with endometritis were similar to those of control cows at \pm 25 DIM, when endometritis diagnosis was performed. 

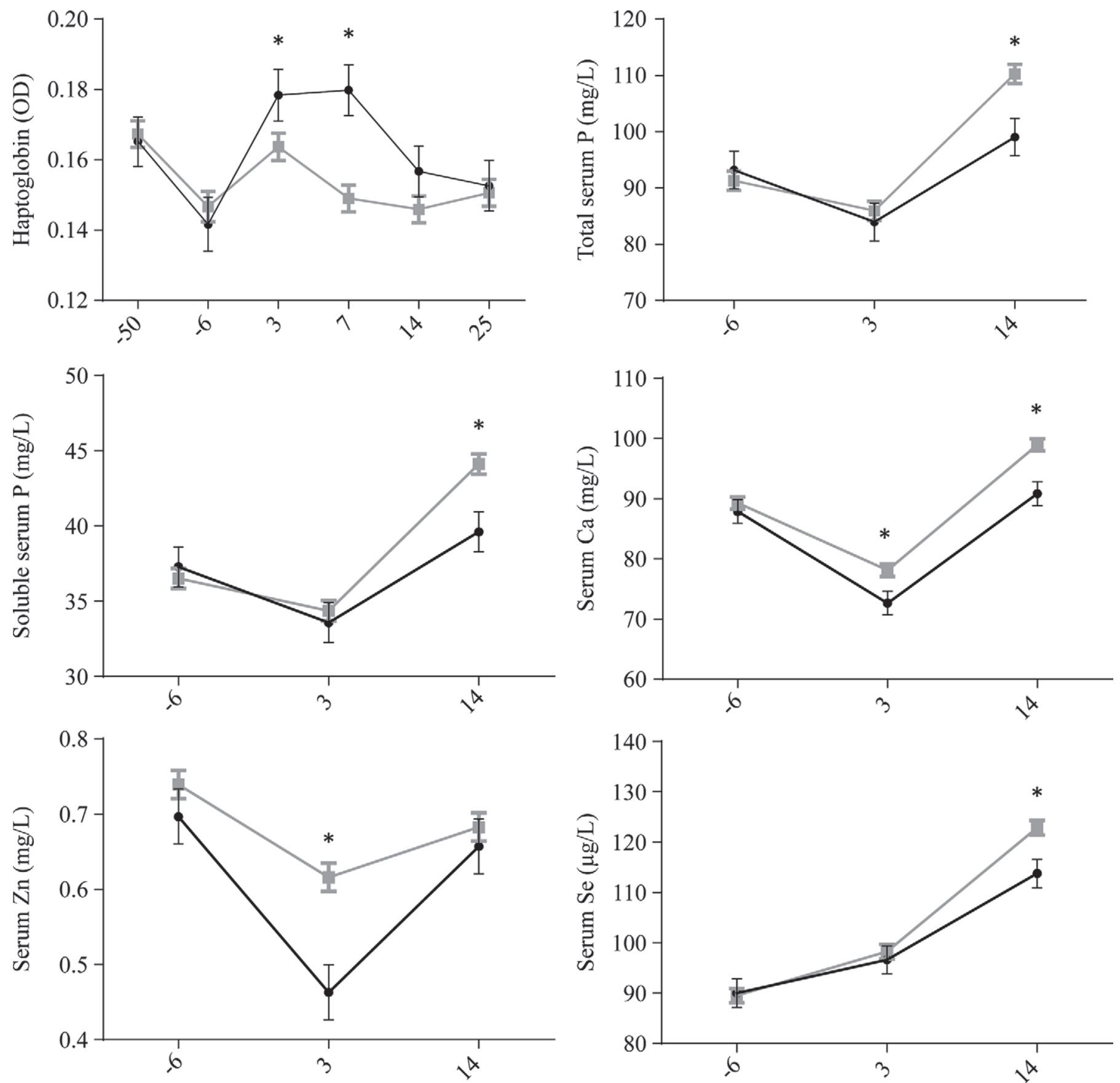

Days relative to parturition

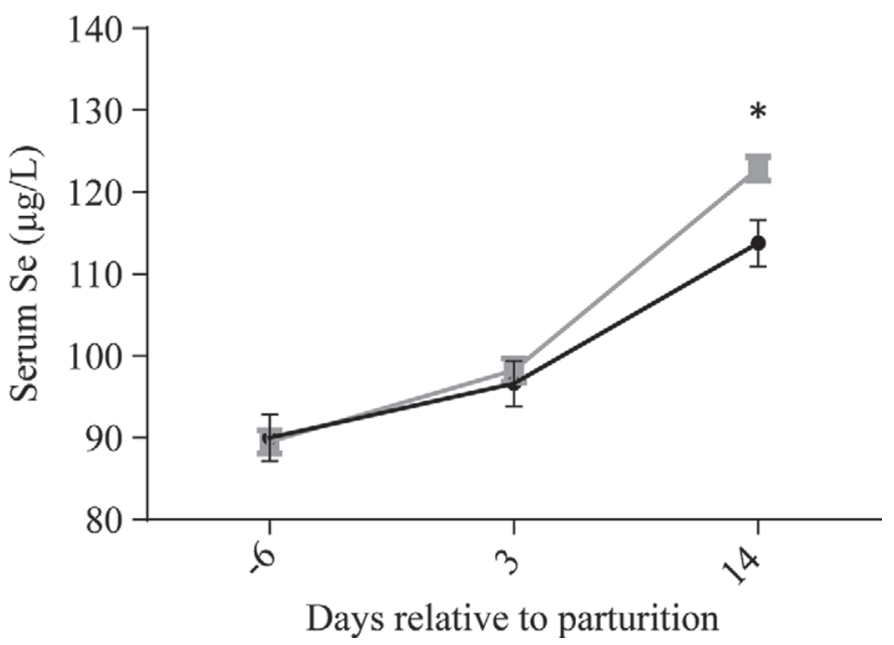

Figure 7. Association between the occurrence of endometritis and day relative to parturition for haptoglobin (optical density units), total P, soluble P, Ca, Se, and Zn. The y-axis represents the LSM \pm SEM in all graphics. Error bars represent the 95\% CI for group means. Cows with endometritis are represented by a black line, and cows that did not have endometritis are depicted by a gray line; an asterisk $(*)$ represents $P$ $<0.05 . \mathrm{OD}=$ optical density.

Subclinical hypocalcaemia was also significantly associated with the incidence of metritis, endometritis, and RP within our study cows. The observed decrease in serum $\mathrm{Ca}$ concentrations after calving found in our study has been previously reported (Kimura et al.,
2006; Martinez et al., 2012). This result contradicts other reports, where low serum levels of Ca were not found to be associated with reproductive diseases (Dubuc et al., 2010; Cheong et al., 2011). Although the correlation between low blood $\mathrm{Ca}$ and uterine disease 
is unspecific, low blood Ca levels may be associated to immune function impairment. Martinez et al., (2012) reported that hypocalcemic cows not only presented decreased circulating neutrophils, but also decreased neutrophils oxidative burst capacity and increased odds of uterine infection. At the cellular level in epithelia, calcium depletion leads to a reduction in the transfer of calcium to mitochondria that slows down the rate of apoptosis (McNaughton and Murray, 2009), potentially increasing the risk for RP and being a significant cause of myometrial dysfunction and atony.

Moreover, the low serum Ca concentrations found in the endometritic cows in our study might be an effect of disease on serum mineral concentrations. As mentioned previously, cows diagnosed with endometritis had a tendency to express higher levels of IL-8 compared with cows that were not affected with endometritis. Interleukin- 8 induces a series of physiological responses required for neutrophil migration and phagocytosis, such as increase of intracellular $\mathrm{Ca}^{2+}$, histamine release, and respiratory burst. Higher IL-8 levels might have induced hypocalcaemia in our endometritic cows. However, Burke et al., (2010) found no association of plasma $\mathrm{Ca}$ through the peripartum period with endometritis (diagnosed at wk 6), and did find that cows with endometritis presented lower plasma $\mathrm{Mg}$ levels.

Although clinical hypomagnesemia is rare in dairy cattle, very low dietary $\mathrm{Na}$ or high dietary $\mathrm{K}$ concentrations may interfere with $\mathrm{Mg}$ transport across the rumen wall and result in clinical disease (Lean et al., 2013). Serum levels of $\mathrm{Mg}$ did not differ statistically among our study cows with metritis and endometritis. However, cows with retained placenta were found to have significantly lower levels of $\mathrm{Mg}$ compared with cows without RP. Total and soluble $\mathrm{P}$ were found to be associated with metritis $(P<0.001)$ in the present study, whereas their interactions with time were significantly associated with endometritis incidence. Cows affected by those diseases presented lower levels of serum $\mathrm{P}$ compared with unaffected cows. Although P and Ca are both closely related, little has been found in the literature regarding the associations between serum $\mathrm{P}$ levels and incidence of uterine diseases. Jamali et al. (2013) showed that the declination of $\mathrm{P}$ levels was associated with elevation of IL-10 levels in women. Interleukin-10, as an antiinflammatory cytokine, may affect immune responses and lead to inappropriate immune responses against pathogenic microbes (Jamali et al., 2013) and, most likely, an increase predisposition to diseases.

The activity of SOD in plasma was not altered by ITMS, nor did it have an association with the incidence of uterine diseases. Knowing that $\mathrm{Zn}$ is an essential component of numerous enzymes (copper-zinc SOD is an abundant intracellular enzyme with an essential role in antioxidant defense), it is interesting to note that serum Zn concentrations were significantly lower in our study in cows with metritis, endometritis, and RP compared with healthy cows. Prepartum serum Zn concentrations decreased progressively in affected animals around 3 DIM and remained below baseline concentrations throughout the first $2 \mathrm{wk}$ of lactation. Superoxide dismutase activity in our study cows could be influenced by the fact that $\mathrm{Cu}$ levels did not differ between affected and nonaffected animals in our study. The $\mathrm{Cu}$ site is the heart of the enzymatic active site where the CuZnSOD protein catalyzes the surplus of superoxide to give dioxygen and hydrogen peroxide (Valentine et al., 2005). Although the precise role of $\mathrm{Zn}$ in the immune system is yet to be fully identified, $\mathrm{Zn}$ has been documented to be involved in several healing processes (Miller, 1970) in the dairy cow, and the inclusion of $\mathrm{Zn}$ supplementation has been previously reported to reduce mastitis cases and improve udder health (Wilde, 2006; Machado et al., 2013). Manspeaker et al. (1987) found that supplementation with Zn reduced the percentage of uterine infections, embryonic mortality, endometrial scarring, and improved the postpartum involution and tone of the pregnant horn for dairy heifers.

Selenium is another essential trace mineral in dairy cattle that provides a significant dietary source of antioxidant defenses. The positive association between cow Se status and its immune response and health is well documented in the literature (Spears and Weiss, 2008; Sordillo, 2013; Salman et al., 2013). Consideration has also been given to RP incidence and Se and vitamin $\mathrm{E}$ supplementation (Wilde, 2006). Fewer studies, however, have been conducted to determine whether an increase in systemic concentrations of Se would affect the prevalence of metritis and endometritis. In the present study, serum Se levels were found to be associated with the incidence of metritis and endometritis. Endometritic cows tended to present lower levels of Se after parturition. Our results support the findings of Machado et al. (2013), who assigned the decrease of incidence of endometritis to Se supplementation, and contradict Rutigliano et al. (2008), where no effect on the prevalence of endometritis was attributed to any source of Se. Plasma Se concentration has also been reported to have a strong positive correlation with GPx activity (Sordillo, 2013). However, no association was found in our study between glutathione dismutase activity and incidence of uterine diseases.

\section{CONCLUSIONS}

In conclusion, we show that ITMS led to an increase in serum levels of $\mathrm{Se}, \mathrm{Zn}$, and $\mathrm{Cu}$, but was not associated 
with energy metabolites, oxidative stress indicators, and serum concentrations of IL- 8 and haptoglobin. Cows suffering from RP had reduced serum concentrations of $\mathrm{Ca}, \mathrm{Mg}, \mathrm{Mo}$, and Zn when compared with cows without RP. However, cows with and without RP showed no differences in concentration of haptoglobin and on GPx and sOD activities. Cows affected with metritis had significantly lower serum concentrations of $\mathrm{Ca}, \mathrm{Mo}, \mathrm{Ps}$, $\mathrm{Pt}$, Se, and Zn than their nonaffected counterparts. The haptoglobin levels of metritic cows increased significantly on $\mathrm{d} 3$ and 7 after parturition; this was not the case for cows without metritis. Concentration of IL-8 and activities of GPx and SOD did not differ between metritic and nonmetritic cows. Serum concentrations of $\mathrm{Ca}, \mathrm{Cu}$, Mo, and $\mathrm{Zn}$ were reduced in cows diagnosed with endometritis in comparison to nonaffected cows. The haptoglobin levels of endometritic cows were reduced when compared with cows without endometritis. Cows diagnosed with endometritis also had increased concentrations of IL-8 when compared with cows without endometritis. The activities of GPx and SOD did not differ between cows with and without endometritis.

\section{REFERENCES}

Bauman, D. E., and W. B. Currie. 1980. Partitioning of nutrients during pregnancy and lactation: A review of mechanisms involving homeostasis and homeorhesis. J. Dairy Sci. 63:1514-1529.

Bicalho, M. L., V. S. Machado, G. Oikonomou, R. O. Gilbert, and R. C. Bicalho. 2012. Association between virulence factors of Escherichia coli, Fusobacterium necrophorum, and Arcanobacterium pyogenes and uterine diseases of dairy cows. Vet. Microbiol. 157:125-131.

Burke, C. R., S. Meier, S. McDougall, C. Compton, M. Mitchell, and J. R. Roche. 2010. Relationships between endometritis and metabolic state during the transition period in pasture-grazed dairy cows. J. Dairy Sci. 93:5363-5373.

Cai, T. Q., P. G. Weston, L. A. Lund, B. Brodie, D. J. McKenna, and W. C. Wagner. 1994. Association between neutrophil functions and periparturient disorders in cows. Am. J. Vet. Res. 55:934-943.

Cebra, C. K., J. R. Heidel, R. O. Crisman, and B. V. Stang. 2003. The relationship between endogenous cortisol, blood micronutrients, and neutrophil function in postparturient holstein cows. J. Vet. Intern. Med. 17:902-907.

Cheong, S. H., D. V. Nydam, K. N. Galvao, B. M. Crosier, and R. O. Gilbert. 2011. Cow-level and herd-level risk factors for subclinical endometritis in lactating holstein cows. J. Dairy Sci. 94:762-770

Contreras, G. A., W. Raphael, S. A. Mattmiller, J. Gandy, and L. M. Sordillo. 2012. Non-esterified fatty acids modify inflammatory response and eicosanoid biosynthesis in bovine endothelial cells. J. Dairy Sci. 95:5011-5023.

Drackley, J. K. 1999. ADSA Foundation Scholar Award. Biology of dairy cows during the transition period: The final frontier? J. Dairy Sci. 82:2259-2273.

Dubuc, J., T. F. Duffield, K. E. Leslie, J. S. Walton, and S. J. LeBlanc. 2010. Risk factors for postpartum uterine diseases in dairy cows. J. Dairy Sci. 93:5764-5771.

Edmonson, A. J., I. J. Lean, L. D. Weaver, T. Farver, and G. Webster. 1989. A body condition scoring chart for Holstein dairy cows. J. Dairy Sci. 72:68-78.

Enjalbert, F., P. Lebreton, and O. Salat. 2006. Effects of copper, zinc and selenium status on performance and health in commercial dairy and beef herds: Retrospective study. J. Anim. Physiol. Anim. Nutr. (Berl.) 90:459-466.
Galligan, C. L., and B. L. Coomber. 2000. Effects of human IL-8 isoforms on bovine neutrophil function in vitro. Vet. Immunol. Immunopathol. 74:71-85.

Galvão, K. N., M. J. Flaminio, S. B. Brittin, R. Sper, M. Fraga, L. Caixeta, A. Ricci, C. L. Guard, W. R. Butler, and R. O. Gilbert. 2010. Association between uterine disease and indicators of neutrophil and systemic energy status in lactating holstein cows. J. Dairy Sci. 93:2926-2937.

Goff, J. P., K. Kimura, and R. L. Horst. 2002. Effect of mastectomy on milk fever, energy, and vitamins A, E, and beta-carotene status at parturition. J. Dairy Sci. 85:1427-1436.

Gordon, J. L., S. J. LeBlanc, and T. F. Duffield. 2013. Evaluation of accuracy of an electronic beta-hydroxybutyrate meter using fresh and stored whole blood and serum from dairy cows. J. Dairy Sci. 96(E-Suppl.):55-56. (Abstr.)

Hammon, D. S., I. M. Evjen, T. R. Dhiman, J. P. Goff, and J. L. Walters. 2006. Neutrophil function and energy status in Holstein cows with uterine health disorders. Vet. Immunol. Immunopathol. 113:21-29

Harrison, J. H. D. D. Hancock, and H. R. Conrad. 1984. Vitamin $\mathrm{E}$ and selenium for reproduction of the dairy cow. J. Dairy Sci. $67: 123-132$

Jamali, Z., M. K. Arababadi, and G. Asadikaram. 2013. Serum levels of IL-6, IL-10, IL-12, IL-17 and IFN-gamma and their association with markers of bone metabolism in vitamin D-deficient female students. Inflammation 36:164-168.

Katoh, N. 2002. Relevance of apolipoproteins in the development of fatty liver and fatty liver-related peripartum diseases in dairy cows. J. Vet. Med. Sci. 64:293-307.

Kimura, K., J. P. Goff, and M. E. Kehrli Jr. 1999. Effects of the presence of the mammary gland on expression of neutrophil adhesion molecules and myeloperoxidase activity in periparturient dairy cows. J. Dairy Sci. 82:2385-2392.

Kimura, K., T. A. Reinhardt, and J. P. Goff. 2006. Parturition and hypocalcemia blunts calcium signals in immune cells of dairy cattle. J. Dairy Sci. 89:2588-2595.

Lean, I. J., R. V. Saun, and P. J. Degaris. 2013. Mineral and antioxidant management of transition dairy cows. Vet. Clin. North Am. Food Anim. Pract. 29:367-386.

Lomborg, S. R., L. R. Nielsen, P. M. Heegaard, and S. Jacobsen. 2008. Acute phase proteins in cattle after exposure to complex stress. Vet. Res. Commun. 32:575-582.

Machado, V. S., M. L. Bicalho, R. V. Pereira, L. S. Caixeta, W. A Knauer, G. Oikonomou, R. O. Gilbert, and R. C. Bicalho. 2013. Effect of an injectable trace mineral supplement containing selenium, copper, zinc, and manganese on the health and production of lactating holstein cows. Vet. J. 197:451-456.

Machado, V. S., G. Oikonomou, M. L. Bicalho, W. A. Knauer, R. Gilbert, and R. C. Bicalho. 2012. Investigation of postpartum dairy cows' uterine microbial diversity using metagenomic pyrosequencing of the 16S rRNA gene. Vet. Microbiol. 159:460-469.

Manspeaker, J. E., M. G. Robl, G. H. Edwards, and L. W. Douglass, 1987. Chelated minerals: Their role in bovine fertility. Vet. Med. 82:951-956.

Martinez, N., C. A. Risco, F. S. Lima, R. S. Bisinotto, L. F. Greco, E. S. Ribeiro, F. Maunsell, K. Galvao, and J. E. Santos. 2012. Evaluation of peripartal calcium status, energetic profile, and neutrophil function in dairy cows at low or high risk of developing uterine disease. J. Dairy Sci. 95:7158-7172.

McDougall, S., R. Macaulay, and C. Compton. 2007. Association between endometritis diagnosis using a novel intravaginal device and reproductive performance in dairy cattle. Anim. Reprod. Sci. 99:9-23.

McNaughton, A. P., and R. D. Murray. 2009. Structure and function of the bovine fetomaternal unit in relation to the causes of retained fetal membranes. Vet. Rec. 165:615-622.

Miller, W. J. 1970. Zinc nutrition of cattle: A review. J. Dairy Sci. $53: 1123-1135$

Ndiweni, N., and J. M. Finch. 1995. Effects of in vitro supplementation of bovine mammary gland macrophages and peripheral blood lym- 
phocytes with alpha-tocopherol and sodium selenite: Implications for udder defences. Vet. Immunol. Immunopathol. 47:111-121.

NRC. 2001. Nutrient Requirements of Dairy Cattle. 7th rev. ed. Natl. Acad. Press, Washington, DC.

Oetzel, G. R. 2013. Oral calcium supplementation in peripartum dairy cows. Vet. Clin. North Am. Food Anim. Pract. 29:447-455.

Pogge, D. J., E. L. Richter, M. E. Drewnoski, and S. L. Hansen. 2012. Mineral concentrations of plasma and liver after injection with a trace mineral complex differ among angus and simmental cattle. J. Anim. Sci. 90:2692-2698.

Roche, J. R., N. C. Friggens, J. K. Kay, M. W. Fisher, K. J. Stafford, and D. P. Berry. 2009. Invited review: Body condition score and its association with dairy cow productivity, health, and welfare. J. Dairy Sci. 92:5769-5801.

Rutigliano, H. M., F. S. Lima, R. L. Cerri, L. F. Greco, J. M. Vilela, V. Magalhaes, F. T. Silvestre, W. W. Thatcher, and J. E. Santos. 2008. Effects of method of presynchronization and source of selenium on uterine health and reproduction in dairy cows. J. Dairy Sci. 91:3323-3336.

Sales, J. N. S., R. V. V. Pereira, R. C. Bicalho, and P. S. Baruselli. 2011. Effect of injectable copper, selenium, zinc and manganese on the pregnancy rate of crossbred heifers (Bos indicus $\times$ Bos taurus) synchronized for timed embryo transfer. Livest. Sci. 142:59-62.

Salman, S., D. Dinse, A. Khol-Parisini, H. Schafft, M. Lahrssen-Wiederholt, M. Schreiner, L. Scharek-Tedin, and J. Zentek. 2013. Colostrum and milk selenium, antioxidative capacity and immune status of dairy cows fed sodium selenite or selenium yeast. Arch. Anim. Nutr. 67:48-61.

Shankar, A. H., and A. S. Prasad. 1998. Zinc and immune function: The biological basis of altered resistance to infection. Am. J. Clin. Nutr. 68:447S-463S.
Sheldon, I. M., D. E. Noakes, A. Rycroft, and H. Dobson. 2001. Acute phase protein responses to uterine bacterial contamination in cattle after calving. Vet. Rec. 148:172-175.

Shuster, D. E., E. K. Lee, and M. E. Kehrli Jr. 1996. Bacterial growth, inflammatory cytokine production, and neutrophil recruitment during coliform mastitis in cows within ten days after calving, compared with cows at midlactation. Am. J. Vet. Res. 57:1569 1575 .

Sordillo, L. M. 2013. Selenium-dependent regulation of oxidative stress and immunity in periparturient dairy cattle. Vet. Med. 2013:154045.

Sordillo, L. M., and S. L. Aitken. 2009. Impact of oxidative stress on the health and immune function of dairy cattle. Vet. Immunol. Immunopathol. 128:104-109.

Spears, J. W., and W. P. Weiss. 2008. Role of antioxidants and trace elements in health and immunity of transition dairy cows. Vet. J. $176: 70-76$.

Underwood, E. J., and N. F. Suttle. 1999. The Mineral Nutrition of Livestock. 3rd ed. CABI Publishing, New York, NY.

Valentine, J. S., P. A. Doucette, and S. Zittin Potter. 2005. Copper-zinc superoxide dismutase and amyotrophic lateral sclerosis. Annu. Rev. Biochem. 74:563-593.

Weiss, W. P. 2005. Antioxidants nutrients, cow health and milk quality. Pages 11-18 in Dairy Cattle Nutrition Workshop, Department of Dairy and Animal Sciences, Penn State, Happy Valley, PA.

Wilde, D. 2006. Influence of macro and micro minerals in the periparturient period on fertility in dairy cattle. Anim. Reprod. Sci. $96: 240-249$. 